\title{
Factors Associated Postoperative Hydrocephalus in Patients with Traumatic Acute Subdural Hemorrhage
}

\author{
Han Kim, M.D., Heui Seung Lee, M.D., Sung Yeol Ahn, M.D., Sung Chun Park, M.D., Ph.D., Won Huh, M.D. \\ Department of Neurosurgery, Myongji Hospital, Goyang, Korea
}

Objective : Postoperative hydrocephalus is a common complication following craniectomy in patients with traumatic brain injury, and affects patients' long-term outcomes. This study aimed to verify the risk factors associated with the development of hydrocephalus after craniectomy in patients with acute traumatic subdural hemorrhage (tSDH).

Methods : Patients with acute traumatic SDH who had received a craniectomy between December 2005 and January 2016 were retrospectively assessed by reviewing the coexistence of other types of hemorrahges, measurable variables on computed tomography (CT) scans, and the development of hydrocephalus during the follow-up period.

Results : Data from a total of 63 patients who underwent unilateral craniectomy were analyzed. Postoperative hydrocephalus was identified in 34 patients (54\%) via brain CT scans. Preoperative intraventricular hemorrhage (IVH) was associated with the development of hydrocephalus. Furthermore, the thickness of SDH $(p=0.006)$ and the extent of midline shift before craniectomy $(p=0.001)$ were significantly larger in patients with postoperative hydrocephalus. Indeed, multivariate analyses showed that the thickness of SDH $(p=0.019)$, the extent of midline shift $(p<0.001)$ and the coexistence of IVH $(p=0.012)$ were significant risk factors for the development of postoperative hydrocephalus. However, the distance from the midline to the craniectomy margin was not an associated risk factor for postoperative hydrocephalus.

Conclusion : In patients with acute traumatic SDH with coexisting IVH, a large amount of SDH, and a larger midline shift, close follow-up is necessary for the early prediction of postoperative hydrocephalus. Furthermore, craniectomy margin need not be limited in acute traumatic SDH patients for the reason of postoperative hydrocephalus.

Key Words : Brain injuries, Traumatic · Hematoma, Subdural · Craniectomy · Hydrocephalus · Intraventricular hemorrhage.

\section{INTRODUCTION}

Postoperative hydrocephalus has been reported to occur in $0.7-86 \%$ of patients with traumatic brain injury, which can lead to unfavorable outcomes ${ }^{1,4,11)}$. Although the cause of hydrocephalus development after craniectomy is considered to be multi factorial, risk factors associated with postoperative hydrocephalus still remain unclear, perhaps due to the varying degrees of traumatic brain injury included and the different surgical proceduresused ${ }^{7,15)}$. Early detection of hydrocephalus could be essential in the long-term postoperative management of patients to minimize postoperative morbidity.

Therefore, we analyzed measurable variables on the preoperative imaging studies with the aim to identify factors associ-

- Received : July 7, 2017 •Revised : August 22, 2017 •Accepted : September 30, 2017

- Address for reprints : Heui Seung Lee, M.D.

Department of Neurosurgery, Myongji Hospital, 55 Hwasu-ro 14beon-gil, Deogyang-gu, Goyang 10475, Korea

Tel : +82-31-810-5114, Fax : +82-31-810-5109, E-mail : antanatia@gmail.com

This is an Open Access article distributed under the terms of the Creative Commons Attribution Non-Commercial License (http://creativecommons.org/licenses/by-nc/4.0) which permits unrestricted non-commercial use, distribution, and reproduction in any medium, provided the original work is properly cited. 
ated with postoperative hydrocephalus by selectively reviewing patients who had undergone unilateral decompressive craniectomy for acute traumatic subdural hemorrhage (SDH).

\section{MATERIALS AND METHODS}

\section{Study population and definition of postoperative hydrocephalus}

A search in the institutional database was conducted to identify patients with acute traumatic SDH who were treated between December 2005 and January 2016. We enrolled patients who had undergone unilateral decompressive craniectomy for hematoma removal. All patients with acute SDH were identified by computed tomography (CT) at the time of admission. We retrospectively reviewed patients according to sex, age, operation record, and occurrence of hydrocephalus during their follow-up. The following factors were included in a between-groups (with postoperative hydrocephalus vs. without postoperative hydrocephalus) analysis : maximal thickness of SDH, extent of midline (ML) shift, presence of intracerebral hemorrhage (ICH), intraventricular hemorrhage (IVH), traumatic subarachnoid hemorrhage ( $\mathrm{tSAH}$ ), and falx $\mathrm{SDH}$, mean distance from the ML to the craniectomy margin, and the presence of postoperative brain swelling.

Postoperative hydrocephalus was defined as enlargement of the ventricle, as per the criteria described by Foroglou and Zander ${ }^{6}$ (lateral and third ventricular enlargement, periventricular lucencies), or the modified Frontal Horn Index $\geq 33 \%{ }^{7)}$ accompanied with periventricular low density on the follow-up brain CT scan that was not observed on the initial preoperative CT scan (Fig. 1).

Exclusion criteria were cases that had received craniotomy, bilateral craniectomy, re-operation cases, asymptomatic ventriculomegaly (such as hydrocephalus ex-vacuo or ventriculomegaly secondary to cerebromalacic change), and cases with a follow-up period of less than one month. This retrospective study was approved by our Institutional Review Board.

\section{Measured variables}

The mean distance from the ML to the medial craniectomy margin was calculated using the shortest and longest distances from the ML to the medial bone margin of craniectomy. The thickness of SDH and extent of ML shift were measured on CT scans (Fig. 2).

The extent and the rate of postoperative brain swelling, which was determined as the swelling of brain parenchyme of the craniectomy side above the skull bone flap was calculated as shown in Fig. 3 (extent of brain swelling/time interval between follow-ups).

The area of craniectomy (CE area) was calculated from the skull X-ray taken postoperatively, as follows : CE area=largest transverse diameter $(\mathrm{D}) \times$ vertical diameter perpendicular to $\mathrm{D}$ (d) $\times \pi / 4^{10)}$ (Fig. 4).

\section{Patient follow-up}

All patients were followed up in our department with a neurological examination and brain CT scan, between 7 and 10 days after craniectomy. The follow-up CT scan was performed for all patients one month after the first admission in order to identify cases of postoperative hydrocephalus.

\section{Statistical analysis}

The SPSS version 22.0 (IBM SPSS., Armonk, NY, USA) was used for statistical analysis. Independent t-tests and MannWhitney U-tests were performed to analyze equality of means

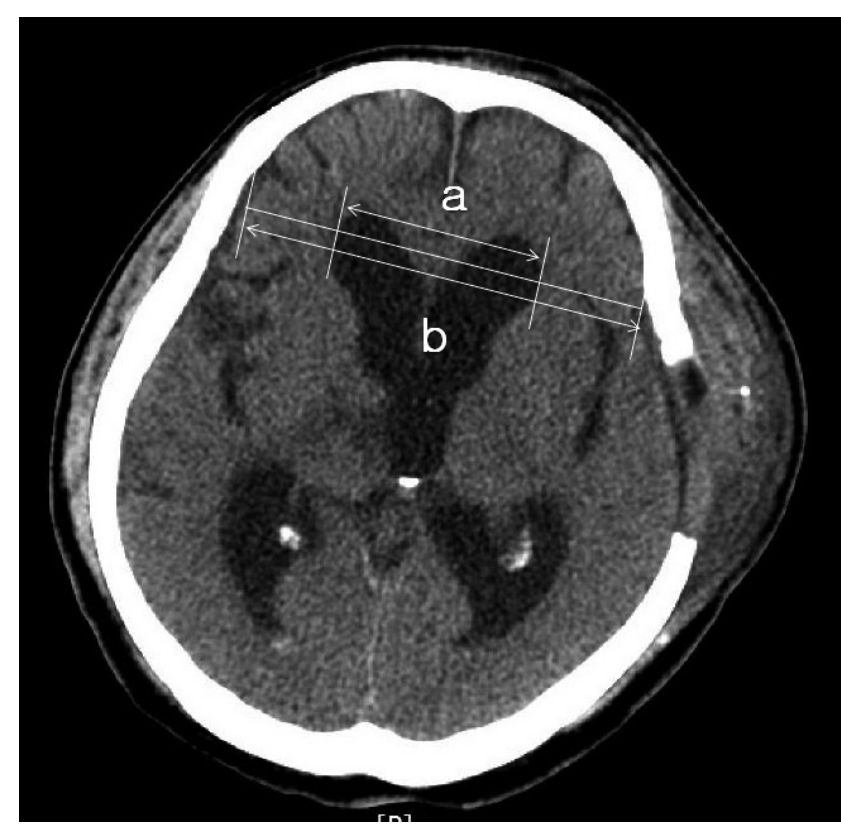

Fig. 1. Definition of postoperative hydrocephalus using the modified Frontal Horn Index (a/b) on postoperative follow-up brain computed tomography scans. 


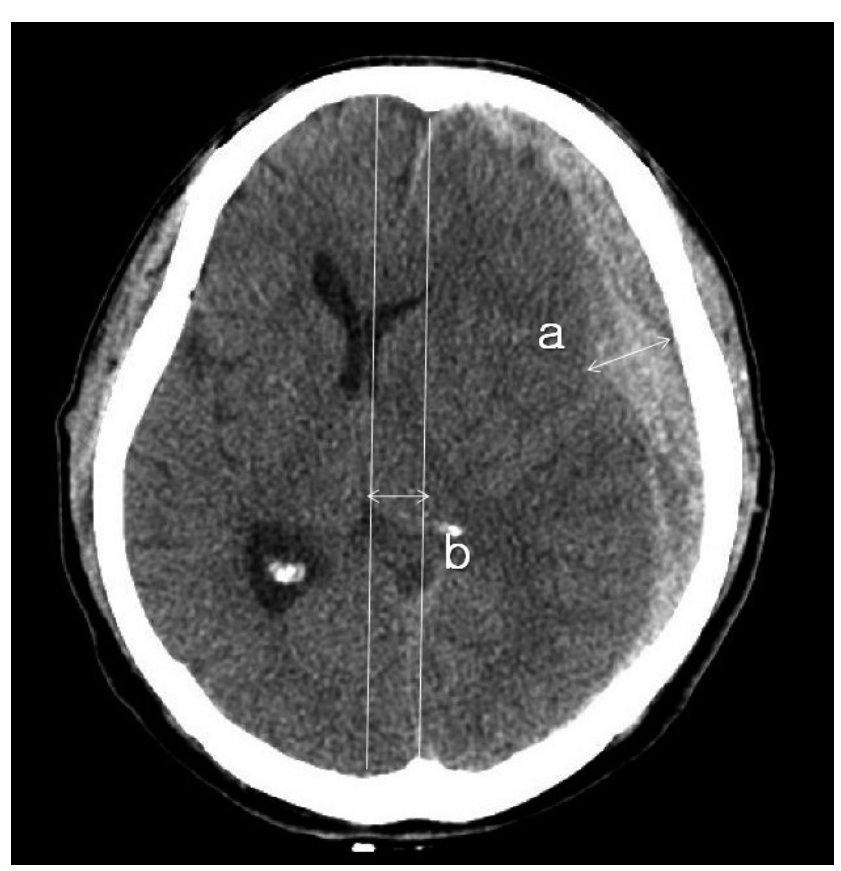

Fig. 2. Measurement of the maximal thickness of SDH (a) and the extent of the ML shift (b). The extent of the ML shift was determined by measuring the distance from the ML of the cranium to the deviated point of the most posterior part of the third ventricle at the same level. SDH : subdural hemorrhage, $\mathrm{ML}$ : midline. for continuous variables. Chi-square tests were performed to determine independence between categorical variables. In the subgroup analysis, the risk of postoperative hydrocephalus was assessed using multivariate tests. Both groups with and without postoperative hydrocephalus were subdivided by the cut-off of the extent of ML shift and thickness of SDH calculated from the areas under the receiver operator characteristic (ROC) curve (AUC). Higher AUC values represent better prediction with the models. Both groups were subdivided according to the mean distance from the ML to craniectomy margin of $25 \mathrm{~mm}$ to calculate the odds ratio using multivariate analysis. $p$-values $\leq 0.05$ were regarded as statistically significant.

\section{RESULTS}

\section{Patient characteristics}

Sixty-three patients underwent unilateral decompressive craniectomy and hematoma removal for acute traumatic SDH between December 2005 and January 2016. Of these, 49 patients $(77.8 \%)$ were male and14 (22.2\%) were female, with a

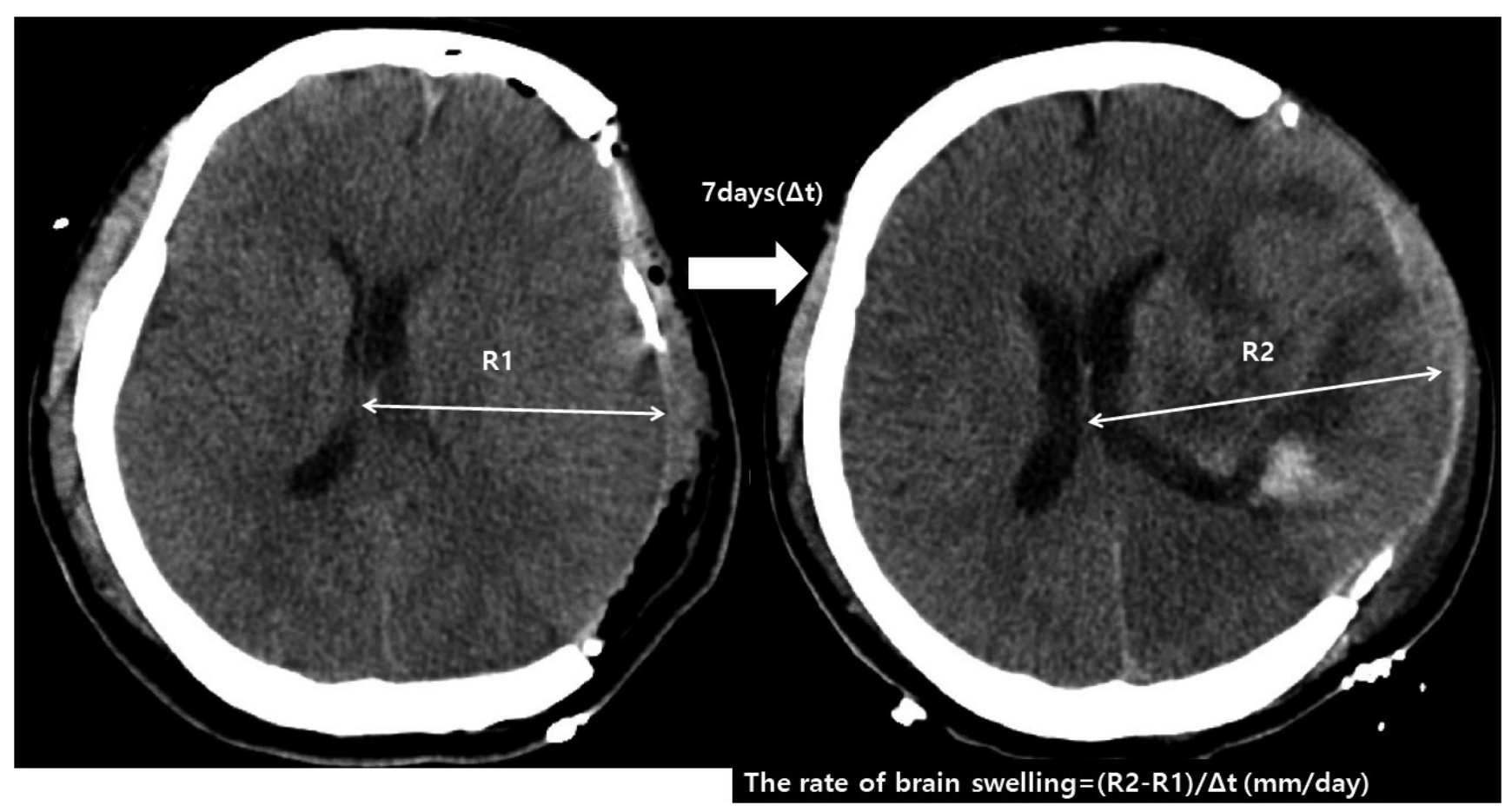

Fig. 3. Axial brain CT scan showing brain swelling on postoperative day 7. The rate of brain swelling during first follow-up period is calculated as follows : (R2-R1)/t (time interval between follow CT scans). CT : computed tomography. 


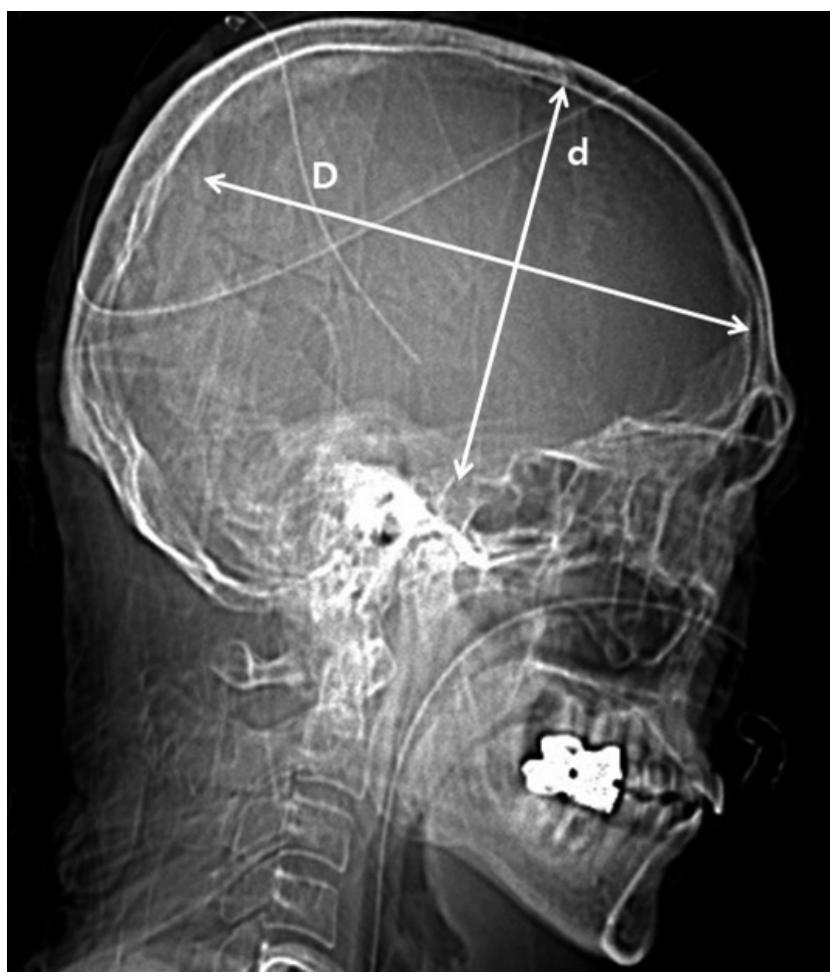

Fig. 4. Calculation of the area of craniectomy (CE area) using postoperative skull $\mathrm{X}$-ray : $\mathrm{CE}$ area=largest transverse diameter $(\mathrm{D}) \times$ vertical diameter perpendicular to $\mathrm{D}(\mathrm{d}) \times \pi / 4$.

male : female ratio of $3.5: 1$. The mean age of patients was $53.67 \pm 18.38$ years (range, $7-85$ years). The median follow-up duration was 47 days (range, 30-146 days). Removal of the unilateral part of the cranium followed by augmentative duroplasty with artificial dura was performed for all patients. The baseline demographics, coexisting hemorrhages at the first admission, and measured variables are shown in Table 1.

\section{Between-group analyses}

Mean age and mean duration of follow-up were not significantly different between the two groups of patients (with/ without postoperative hydrocephalus). Among the coexisting hemorrhages at the first admission, intraventricular hemorrhage was significantly associated with postoperative hydrocephalus showing the occurrence of $88.2 \%$ ( $p=0.001)$. Brain swelling after craniectomy at postoperative day 7 to 10 was not associated with postoperative hydrocephalus $(p=0.38)$ and the rate of postoperative brain swelling was not significantly different between groups ( $p=0.21$ ) (Table 1). The mean distance from the ML to the medial craniectomy margin was $28.57 \pm$
$9.29 \mathrm{~mm}$ (range, 13.86 to $52.83 \mathrm{~mm}$ ) for all patients, and was not significantly different between the two patient groups (26.82 $\pm 8.02 \mathrm{~mm}$ for patients with postoperative hydrocephalus, and $30.07 \pm 10.13 \mathrm{~mm}$ for patients without postoperative hydrocephalus).

Among the measured variables, the maximal thickness of $\mathrm{SDH}$ and the extent of ML shift were significantly larger in the group with postoperative hydrocephalus (Table 1). The maximal thickness of SDH was significantly larger in the postoperative hydrocephalus group compared to the without postoperative hydrocephalus group $(17.54 \pm 6.68 \mathrm{~mm}$ vs. $12.91 \pm 5.74$ $\mathrm{mm}, p=0.006)$. The extent of ML shift was also significantly larger in the postoperative hydrocephalus group compared to the without postoperative hydrocephalus group $(13.90 \pm 5.13$ $\mathrm{mm}$ vs. $9.99 \pm 3.72 \mathrm{~mm}, p=0.001$ ).

The mean area of the craniectomy was $84.49 \pm 17.84 \mathrm{~cm}^{2}$ in the postoperative hydrocephalus group and $82.21 \pm 14.61 \mathrm{~cm}^{2}$ in the group without hydrocephalus, which is not significantly different $(p=0.71)$. However, the ratio of the craniectomy area to the maximal thickness of SDH and ratio craniectomy area to the extent of ML shift were significantly lower in the group of postoperative hydrocephalus compared to the group without postoperative hydrocephalus (Table 1).

\section{Risk of postoperative hydrocephalus according to measured variables}

The AUC was $0.754 \pm 0.064$ with a cut-off value of $11.99 \mathrm{~mm}$ for the extent of ML shift, and $0.701 \pm 0.065$ with a cut-off value of $18.29 \mathrm{~mm}$ for the maximal thickness of SDH (Fig. 5). We selected the variables that showed association with postoperative hydrocephalus, and defined the risk groups using cut-off values from the ROC curve and the distance from the ML to the craniectomy margin of $25 \mathrm{~mm}$. Significant risk factors for the development of postoperative hydrocephalus were identified to include the maximal thickness of SDH $(p=0.019)$, the extent of the ML shift $(p<0.001)$, and the coexistence of IVH ( $p=0.012)$ (Table 2).

\section{DISCUSSION}

Although various reports exist on the incidence of postoperative hydrocephalus, this is the first study to retrospectively analyze a select group of patients with acute traumatic SDH 
Table 1. Demographic, imaging, and clinical data for 63 patients with acute traumatic SDH

\begin{tabular}{|c|c|c|c|c|}
\hline & Total $(n=63)$ & $\begin{array}{c}\text { Patients without } \\
\text { hydrocephalus ( } n=29,46 \%)\end{array}$ & $\begin{array}{c}\text { Patients with } \\
\text { hydrocephalus }(n=34,54 \%)\end{array}$ & $p$-value \\
\hline Age (years) & $53.67 \pm 18.38$ & $49.1 \pm 19.22$ & $57.56 \pm 16.95$ & 0.08 \\
\hline Sex & & & & 0.07 \\
\hline Male & $49(77.8)$ & $26(53.1)$ & $23(46.9)$ & \\
\hline Female & $14(22.2)$ & $3(21.4)$ & $11(78.6)$ & \\
\hline Follow-up duration (days) & $55.29 \pm 27.25$ & $57.59 \pm 30.9$ & $57.59 \pm 30.9$ & 0.85 \\
\hline \multicolumn{5}{|l|}{ Coexisting hemorrhages } \\
\hline Traumatic ICH & $42(66.7)$ & $20(47.6)$ & $22(52.4)$ & 0.79 \\
\hline Traumatic SAH & $45(71.4)$ & $20(44.4)$ & $25(55.6)$ & 0.78 \\
\hline IVH & $17(27)$ & $15(88.2)$ & $2(11.8)$ & 0.001 \\
\hline Falx SDH & $21(33.3)$ & $8(38.1)$ & $13(61.9)$ & 0.43 \\
\hline Postoperative infection & $9(14.3)$ & $4(44.4)$ & $5(55.6)$ & $>0.99$ \\
\hline Postoperative brain swelling & 49 (77.8) & $21(42.9)$ & $28(57.1)$ & 0.38 \\
\hline Maximal SDH thickness (mm) & $15.41 \pm 6.64$ & $12.91 \pm 5.74$ & $17.54 \pm 6.68$ & 0.006 \\
\hline Mean distance (ML to CE margin) (mm) & $28.57 \pm 9.29$ & $26.82 \pm 8.02$ & $30.07 \pm 10.13$ & 0.26 \\
\hline $10-20$ & & $5(45.5)$ & $6(54)$ & 0.23 \\
\hline $20-30$ & & $16(57.1)$ & $12(42.9)$ & \\
\hline$>30$ & & $8(33.3)$ & $16(66.7)$ & \\
\hline ML shift (mm) & $12.10 \pm 4.91$ & $9.99 \pm 3.72$ & $13.90 \pm 5.13$ & 0.001 \\
\hline Swelling rate (mm) & $0.52 \pm 0.73$ & $0.49 \pm 0.74$ & $0.54 \pm 0.73$ & 0.21 \\
\hline CE area $\left(\mathrm{cm}^{2}\right)$ & $83.44 \pm 16.34$ & $82.21 \pm 14.61$ & $84.49 \pm 17.84$ & 0.71 \\
\hline CE area to SDH thickness & $6.82 \pm 4.01$ & $8.01 \pm 4.38$ & $5.81 \pm 3.4$ & 0.026 \\
\hline CE area to ML shift & $8.18 \pm 4.62$ & $9.3 \pm 3.59$ & $7.19 \pm 5.22$ & 0.002 \\
\hline
\end{tabular}

Values are presented as mean \pm standard deviation or number (\%). ICH : intracerebral hemorrhage, $\mathrm{SAH}$ : subarachnoid hemorrhage, IVH : intraventricular hemorrhage, $\mathrm{SDH}$ : subdural hemorrhage, $\mathrm{ML}$ : midline, $\mathrm{CE}$ : craniectomy

who underwent unilateral craniectomy. In this population, we found that hydrocephalus developed in 54\% of patients after unilateral craniectomy.

Age has been previously reported as an influencing factor for the development of hydrocephalus in patients with traumatic brain injury ${ }^{912,13)}$. For example, older age has been identified as a risk factor for hydrocephalus in patients with $\mathrm{tSAH}^{12)}$, whereas younger age was associated with shunt-dependent hydrocephalus after decompressive craniectomy in a recent study by Vedantam et al. ${ }^{13)}$. However, as in several studies previously published ${ }^{3,4,10)}$, we did not find age to be associated with the occurrence of postoperative hydrocephalus.

Another suggested risk factor for the development of hydrocephalus in the patients with traumatic brain has been different types of coexisting hemorrhages at the time of admis- $\operatorname{sion}^{9,12,13}$. However, we found that only IVH was significantly associated with postoperative hydrocephalus, and that $\mathrm{tSAH}$, ICH, and the falx SDH were not.

It has been suggested that craniectomy may play a role in the flattening of the normal dicrotic intracranial waveform due to the transmission of the pressure pulse out through the open cranium, which leads to decreased cerebrospinal fluid (CSF) outflow to the arachnoid granulations ${ }^{2,6,16)}$. Thus, a medial margin of a craniectomy close to the ML has been suggested as a risk factor for the development of hydrocephalus, via an impairment of hydrodynamic CSF circulation ${ }^{4,5,14)}$. For example, De Bonis et al. ${ }^{4)}$ reported a markedly increased risk of postoperative hydrocephalus in patients with a superior limit of craniectomy less than $25 \mathrm{~mm}$. However, the mean distance from the ML to the medial craniectomy margin was not 

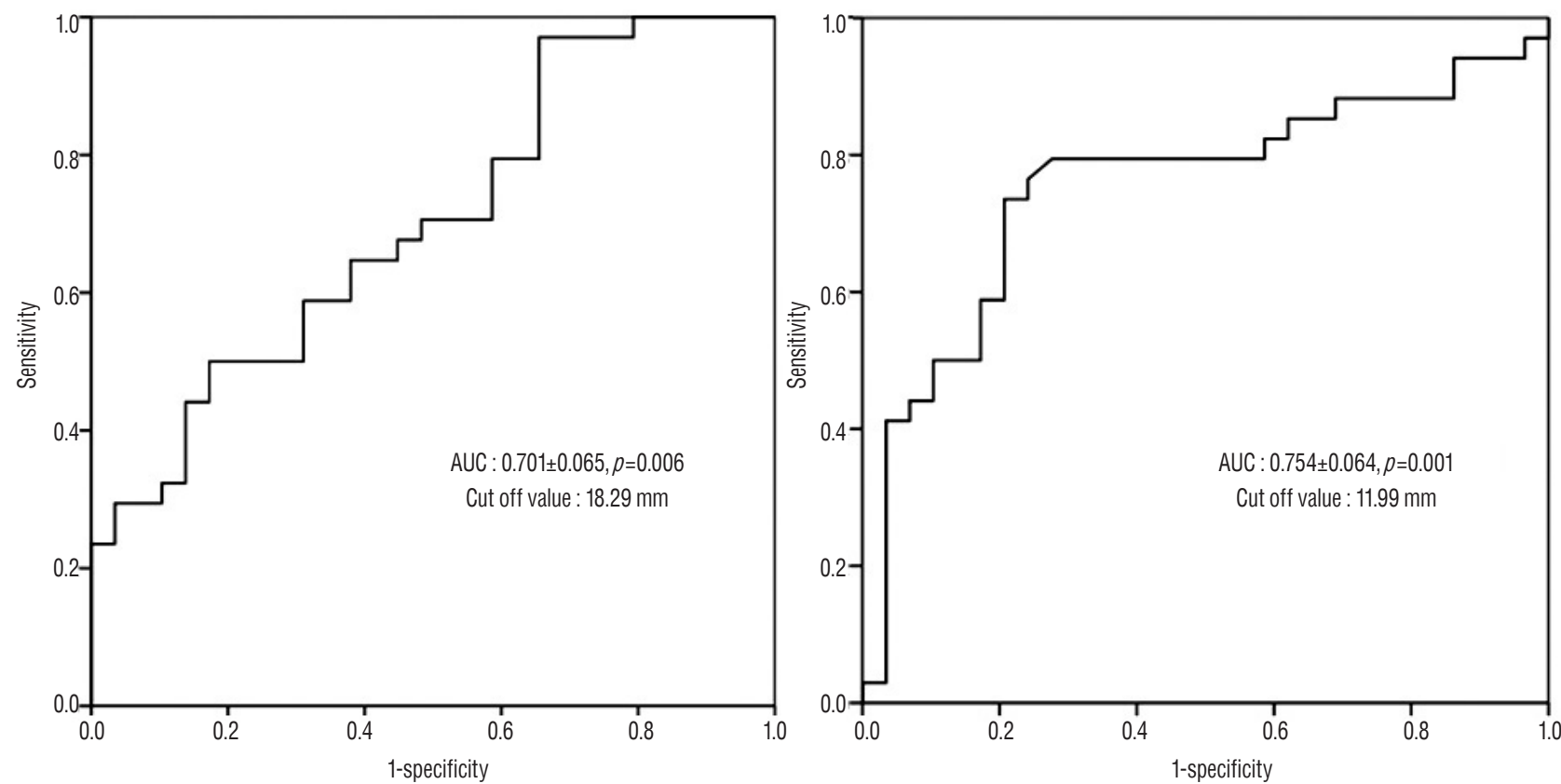

Fig. 5. Receiver operating characteristics curves for prediction of the development of postoperative hydrocephalus using the maximal thickness of SDH (A) and the extent of $M L$ shift (B). SDH : subdural hemorrhage, $M L$ : midline.

Table 2. Multiple logistic regression model for factors associated with postoperative hydrocephalus

\begin{tabular}{|c|c|c|c|c|c|c|}
\hline & \multirow{2}{*}{$\begin{array}{l}\text { Hydrocephalus } \\
(n=34,54 \%)\end{array}$} & \multirow{2}{*}{$\begin{array}{l}\text { No hydrocephalus } \\
(n=29,46 \%)\end{array}$} & \multirow{2}{*}{$p$-value } & \multicolumn{3}{|c|}{ Multivariate analysis } \\
\hline & & & & OR & $95 \% \mathrm{Cl}$ & $p$-value \\
\hline Maximal SDH thickness $>18 \mathrm{~mm}$ & $17(73.9)$ & $6(26.1)$ & 0.02 & 3.83 & $1.25-11.77$ & 0.019 \\
\hline ML Shift >12 mm & $25(80.6)$ & $6(19.4)$ & $<0.001$ & 10.65 & $3.28-34.59$ & $<0.001$ \\
\hline Mean distance (ML to CE margin) <25 mm & $14(50)$ & $14(50)$ & 0.62 & 0.75 & $0.28-2.04$ & 0.57 \\
\hline IVH & $15(88.2)$ & $2(11.8)$ & 0.001 & 9.2 & $1.63-52.14$ & 0.012 \\
\hline
\end{tabular}

Values are presented as number (\%). OR : odds ratio, $\mathrm{Cl}$ : confidence interval, SDH : subdural hemorrhage, $\mathrm{ML}$ : midline, CE : craniectomy, IVH : intraventricular hemorrhage

significantly different between those with and without postoperative hydrocephalus; furthermore, the risk of developing hydrocephalus was not significantly higher in the group in which the distance from the ML was less than $25 \mathrm{~mm}$ in our study. Furthermore, stratifying patients according to the distance from the ML, there was no association between distance from the ML and the development of postoperative hydrocephalus. According to these results, the mean distance from the ML to the medial craniectomy margin does not affect the development of postoperative hydrocephalus unless the craniectomy margin involves the superior sagittal sinus.

On the other hand, we consider that the margin of duroplasty might be important to consider, so that injury to the sagittal sinus or bridging veins can be avoided. Duroplasty was performed lateral to the craniectomy margin in all patients of our study, which did not invade the bridging vein or sagittal sinus. Therefore, the medial margin of craniectomy need not be limited to be close to the ML for the reason of development of postoperative hydrocephalus.

The extent of ML shift and the thickness of SDH at the time of admission were significantly higher in the group with postoperative hydrocephalus. We thus identified a diffuse ML shift and thickness of SDH to be independent risk factors for the development of postoperative hydrocephalus. This replicates previous findings in which basal cistern compression and diffuse ML shift were reported to be risk factors for the 
development of subdural hygroma ${ }^{8,18)}$, and were also considered to be associated with the development of postoperative hydrocephalus because both the extent of ML shift and thickness of SDH can cause compression of the basal cistern, which interferes with the CSF pathway.

The size of the craniectomy has also been associated with a higher risk of postoperative hydrocephalus ${ }^{3,10)}$. However, the result of this study showed no difference in the size of craniectomy between groups with and without postoperative hydrocephalus. We assume that previous studies might include patients with a large amount of SDH in the case of large-sized craniectomy. On the other hands, the ratio of craniectomy area to the maximal thickness of SDH and ML shift (craniectomy area/SDH thickness and craniectomy area/ML shift) were significantly lower in the group with postoperative hydrocephalus compared to that without postoperative hydrocephalus, which means SDH thickness and ML shift are more affective variables. In the case of large amount of SDH with significant ML shift, inadequately small sized craniectomy may increase the risk of brain strangulation that can lead to venous infarction. Therefore, we suggest in this study that amount of SDH and the extent of ML shift should be considered prior to the size of craniectomy for the postoperative prognosis and the size and the medial margin of the craniectomy or the size of craniectomy do not need to be limited when there is a large amount of SDH and a large extent of ML shift.

To our knowledge, the present study is the first study to quantitatively analyze the measurable variables on CT scans to show the association of both $\mathrm{M}$ shift and the thickness of SDH with the occurrence of postoperative hydrocephalus and we only evaluated the case of unilateral craniectomy in patients with acute traumatic SDH to make the study group more homogeneous than those of previous studies. Thus, in the case of traumatic brain injury, results and analyses of this study may more reliably predict hydrocephalus in cases of unilateral craniectomy.

Cases of postoperative subdural effusion or hygroma were excluded from further analysis in our study, because subdural CSF collection often resolves with conservative management or during cranioplasty procedures, and less commonly causes the manifestation of neurologic deterioration than doeshydrocephalus $^{17}$.

There were several limitations to this study. First, due to the limited number of patients with acute traumatic SDH, relatively few cases of postoperative hydrocephalus were analyzed, which limits the power to identify risk factors for the development of hydrocephalus. Second, this was a retrospective study based on radiological findingsthat has a limitation of evaluating whether patients needed shunt operation for CSF diversion. Therefore, future research should focus on recruiting more cases, and should implement long-term follow-up and a more thorough review of patients in a prospective manner.

\section{CONCLUSION}

The occurrence of postoperative hydrocephalus in patients with acute traumatic SDH is affected by the initial amount of SDH and the extent of the ML shift. The medial margin of craniectomy, however, was not associated with postoperative hydrocephalus. Therefore, there seems to be no need to limit the size of craniectomy when there is large amount of SDH accompanied with ML shift. Close follow-up should be necessary for the patients with risk factors for the development of hydrocephalus compatible with radiological study.

\section{References}

1. Cardoso ER, Galbraith $S$ : Posttraumatic hydrocephalus--a retrospective review. Surg Neurol $23:$ 261-264, 1985

2. Carvi Y Nievas MN, Hollerhage HG : Early combined cranioplasty and programmable shunt in patients with skull bone defects and CSFcirculation disorders. Neurol Res 28 : 139-144, 2006

3. Choi I, Park HK, Chang JC, Cho SJ, Choi SK, Byun BJ : Clinical factors for the development of posttraumatic hydrocephalus after decompressive craniectomy. J Korean Neurosurg Soc 43 : 227-231, 2008

4. De Bonis P, Pompucci A, Mangiola A, Rigante L, Anile C : Post-traumatic hydrocephalus after decompressive craniectomy: an underestimated risk factor. J Neurotrauma 27 : 1965-1970, 2010

5. De Bonis P, Sturiale CL, Anile C, Gaudino S, Mangiola A, Martucci M, et al. : Decompressive craniectomy, interhemispheric hygroma and hydrocephalus: a timeline of events? Clin Neurol Neurosurg 115 : 1308 1312, 2013

6. Foroglou $\mathrm{G}$, Zander $\mathrm{E}$ : Post-traumatic hydrocephalus and measurement of cerebrospinal fluid pressure. Acta Radiol Diagn (Stockh) 13 : 524 530, 1972

7. Fotakopoulos G, Tsianaka E, Siasios G, Vagkopoulos K, Fountas K : Posttraumatic hydrocephalus after decompressive craniectomy in 126 patients with severe traumatic brain injury. J Neurol Surg A Cent Eur 
Neurosurg $77: 88-92,2016$

8. Jeon SW, Choi JH, Jang TW, Moon SM, Hwang HS, Jeong JH : Risk factors associated with subdural hygroma after decompressive craniectomy in patients with traumatic brain injury : a comparative study. J Korean Neurosurg Soc 49 : 355-358, 2011

9. Jiao QF, Liu Z, Li S, Zhou LX, Li SZ, Tian W, et al. : Influencing factors for posttraumatic hydrocephalus in patients suffering from severe traumatic brain injuries. Chin J Traumatol 10 : 159-162, 2007

10. Ki HJ, Lee HJ, Lee HJ, Yi JS, Yang JH, Lee IW : The risk factors for hydrocephalus and subdural hygroma after decompressive craniectomy in head injured patients. J Korean Neurosurg Soc 58 : 254-261, 2015

11. Marmarou A, Foda MA, Bandoh K, Yoshihara M, Yamamoto T, Tsuji O, et al. : Posttraumatic ventriculomegaly: hydrocephalus or atrophy? A new approach for diagnosis using CSF dynamics. J Neurosurg 85 : 1026-1035, 1996

12. Tian HL, Xu T, Hu J, Cui YH, Chen H, Zhou LF : Risk factors related to hydrocephalus after traumatic subarachnoid hemorrhage. Surg Neurol 69 : 241-246; discussion 246, 2008

13. Vedantam A, Yamal JM, Hwang H, Robertson CS, Gopinath SP : Factors associated with shunt-dependent hydrocephalus after decompressive craniectomy for traumatic brain injury. J Neurosurg, 2017 [Epub ahead of print]

14. Wang QP, Ma JP, Zhou ZM, You C : Impact of operation details on hydrocephalus after decompressive craniectomy. Neurosciences (Riyadh) $21:$ 10-16, 2016

15. Wani AA, Ramzan AU, Tanki H, Malik NK, Dar BA : Hydrocephalus after decompressive craniotomy: a case series. Pediatr neurosurg 49 : 287-291, 2013.

16. Waziri A, Fusco D, Mayer SA, McKhann GM 2nd, Connolly ES Jr : Postoperative hydrocephalus in patients undergoing decompressive hemicraniectomy for ischemic or hemorrhagic stroke. Neurosurgery 61 : 489493; discussion 493-494, 2007

17. Yang XF, Wen L, Shen F, Li G, Lou R, Liu WG, et al. : Surgical complications secondary to decompressive craniectomy in patients with a head injury: a series of 108 consecutive cases. Acta Neurochir (Wien) 150 : 1241-1247; discussion 1248, 2008

18. Yuan Q, Wu X, Yu J, Sun Y, Li Z, Du Z, et al. : Subdural hygroma following decompressive craniectomy or non-decompressive craniectomy in patients with traumatic brain injury: clinical features and risk factors. Brain Inj 29 : 971-980, 2015 